\title{
PERSPECTIVES
}

TIMELINE

\section{The prospect for bacteriophage therapy in Western medicine}

\section{Carl R. Merril ${ }^{*}$, Dean Scholl ${ }^{\star}$ and Sankar L. Adhya*}

Bacteriophage (phage) have been used for clinical applications since their initial discovery at the beginning of the twentieth century. However, they have never been subjected to the scrutiny - in terms of the determination of efficacy and pharmacokinetics of therapeutic agents - that is required in countries that enforce certification for marketed pharmaceuticals. There are a number of historical reasons for this deficiency, including the overshadowing discovery of the antibiotics. Nevertheless, present efforts to develop phage into reliable antibacterial agents have been substantially enhanced by knowledge gained concerning the genetics and physiology of phage in molecular detail during the past 50 years. Such efforts will be of importance given the emergence of antibiotic-resistant bacteria.

The first widely used antibiotic, penicillin, was discovered 75 years ago. Since then, the production of antibiotics has grown into an industry with a market value estimated to exceed US \$25 billion per year. Although antibiotics have saved countless lives, their widespread use has contributed to an increase in the incidence of antibiotic-resistant bacterial strains. For example, at the beginning of the antibiotic era Streptococcus pneumoniae was highly sensitive to penicillin, yet now, in some regions of the world, $25 \%$ of S. pneumoniae strains are resistant $t^{1}$. In addition, $70 \%$ of hospital-acquired bacterial infections in the United States are now resistant to one or more of the main antibiotics ${ }^{2}$ and greater than $50 \%$ of clinical Staphylococcus aureus isolates in Japan are now multidrug resistant ${ }^{3}$. However, antibiotics are only one example of antibacterial entities that have arisen through the evolutionary competition between other species and bacteria. Another entity, the bacterial viruses (bacteriophage or PHAGE), might provide an alternative to fill the space created in the physician's toolkit left by the dearth of new medicines to combat infections with antibiotic-resistant bacteria (FIG. 1).

The ability of phage to replicate exponentially and kill pathogenic strains of bacteria indicates that they should play a vital role in our armamentarium for the treatment of infectious diseases. In fact, such an application for phage was apparent to Felix d'Herelle after they were discovered by Twort in 1915 (REFS 4,5). d'Herelle was encouraged by his early experiments, in which he used phage to treat avian typhosis in chickens, shigella dysentery in rabbits and humans with bacillary dysentery. Following the reported successes of these experiments, d'Herelle travelled around the world stimulating basic and clinical phage research. Inspired by d'Herelle, the British medical officer Lieutenant Colonel Morison used phage for the prophylactic treatment of cholera epidemics in the Naogaon region of India from 1930 to 1935. In 1932, Morison reported few cholera deaths in the phage-treated Naogaon region, in contrast to the 474 deaths recorded in the Habiganj region which refused treatment $t^{6,7}$.

d'Herelle was also important in the establishment of a phage institute in Tbilisi, Soviet Georgia. This institute produced large quantities of phage for antibacterial therapy during and immediately following the Second World War and the institute is still actively pursuing phage therapy applications. Applications of phage as pursued in the Soviet Union (as well as Poland) have been extensively reviewed ${ }^{8,9}$. The authors of these reviews noted that the details of phage dosages are presented primarily as qualitative data and that clinical criteria were generally reported in a 'sketchy' manner. For these reasons, most of the studies from Eastern Europe will not meet the present standards for pharmaceutical approval in countries that require certification based on the results of efficacy and pharmacokinetic studies in animals and humans.

There was also an interest, in the 1920 s and 1930s, in phage therapy in the United States. The large pharmaceutical company Eli Lilly \& Co. sold 'Staphylo jel', and other phage 'jel' labelled products, for the treatment of Streptococcus spp. and colon bacilli infections. E. R. Squibb \& Sons and the Swan-Myers division of Abbott Laboratories marketed a bacteriophage filtrate preparation for Staphylococcus spp., and combined bacteriophage filtrate preparations for Staphylococcus spp. and colon bacilli, respectively ${ }^{10}$. Despite this initial enthusiasm for phage products, clinical failures, theoretical concerns and the overshadowing development of antibiotics resulted in the abandonment of phage therapy in the United States and much of Western Europe ${ }^{10-20}$ (TIMELINE).

\section{Re-examination of potential efficacy} Despite the chequered history of phage therapy, concerns over the increased incidence of antibiotic resistance has led investigators to examine the possibility of developing phage therapy into a reliable clinical tool. In one recently published animal study, a vancomycin-resistant Enterococcus faecium strain was used to induce a fatal bacteraemia (within 48 hours) in mice. Treatment with a single intraperitoneal injection of phage 45 minutes after the bacterial challenge was sufficient to rescue $100 \%$ of the animals, and even when treatment was delayed until the 


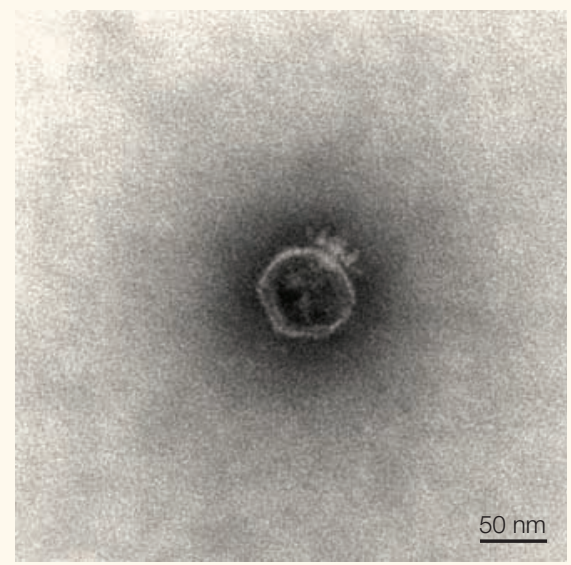

Figure 1 | Electron micrograph of phage. This is an Escherichia coli phage. Phage can range from filamentous to spherical structures. However, many of them have a distinct head, containing their DNA, and a tail-like structure that can bind to bacterial receptors.

animals were moribund, phage administration was able to rescue $50 \%$ of the mice ${ }^{21}$. Similar results have been obtained using phage to treat animals infected with methicillin-resistant $S$. aureus ${ }^{22}$. In addition, phage have been used to treat Acinetobacter baumanii or Pseudomonas aeruginosa and animals with local and systemic disease caused by Vibrio vulnificus ${ }^{23,24}$.

Phages are also capable of treating antibiotic-resistant intracellular pathogens. Broxmeyer et al. ${ }^{25}$ have demonstrated that it is possible to use Mycobacterium smegmatis, an avirulent mycobacterium, as a vector to deliver the LYTIC PHAGE TM4 to treat intracellular mycobacterium infections (with either
Mycobacterium avium or Mycobacterium tuberculosis) in macrophages. Phages have also been effective in the treatment of nonsystemic infections, such as gastrointestinal infections caused by enteropathogenic strains of Escherichia coli in calves, pigs and lambs and ileocecitis caused by Clostridium difficile in hamsters ${ }^{26-29}$. Phages have also been shown to be effective in preventing the destruction of skin grafts by P. aeruginosa ${ }^{30}$. Terrestrial animals are not the only candidates for phage therapy, as recent studies have shown that phage can be used to treat bacterial diseases of fish in aquiculture ${ }^{31}$, bacterial blight of geranium ${ }^{32}$ and bacterial spot on tomatoes ${ }^{33}$.

\section{Phage pharmacokinetics}

Although phage therapy has a long history, pharmacokinetic data are still rudimentary. Most clinical applications of phage therapy have relied on the oral administration of phage preparations. This choice offers the possibility of reducing side effects from contaminants, including ENDOTOXINS and EXOTOXINS, but it might not provide the most effective therapeutic regimen $(s)^{34}$. Some early practitioners of phage therapy recognized the need for pharmacokinetic information. The first effort to obtain such data in 1921 led to the observation that phage injected into the circulatory system of rabbits could still be found in the spleen long after the elimination of phage from other organs or the blood ${ }^{35}$. This finding was corroborated by both qualitative and quantitative experiments, in which a decrease in phage titre in the blood of mice injected with a Staphylococcus phage (a decrease of four orders of magnitude of phage titres was observed 5 minutes after intravenous injection, and by seven logs two hours later) was attributed to elimination by the reticulo-endothelial system (RES) ${ }^{17,36}$.

The relative roles of the liver and spleen in this process were determined by using ${ }^{51} \mathrm{Cr}$-labelled phage. In these experiments the liver phagocytosed more than $99 \%$ of the phage in the circulatory system and inactivated the phage at a higher rate than the spleen $^{37}$. Antibodies associated with the ADAPTIVE IMMUNE SYSTEM were not involved in this process, as demonstrated by experiments using germ-free mice that had no detectable antibodies to the phage strain used. Systemically administered phages were rapidly eliminated from the circulation of the germfree mice. Furthermore, these quantitative experiments demonstrated that the oral administration of phage was not an effective method for delivery to systemic sites ${ }^{34}$ (FIG. 2). Recognition that the RES can remove a significant proportion of administered phage led to the development of a serial passage selection method to isolate phage mutants with a greater capacity to remain in the circulatory system of the mouse. These 'long-circulating' phage mutants also proved to be more effective therapeutically ${ }^{38}$.

In studying the pharmacokinetics of phage it should be noted that phage DNA, like any other foreign DNA, can get into mammalian cells and, on rare occasions, into chromosomes $^{39-41}$. There have also been reports of phage-induced enzyme activity in mammalian cells, albeit at low levels, following exposure to phage or phage $\mathrm{DNA}^{42,43}$. Although there are efforts underway to enhance the capability of phage to serve as

\section{Timeline | Highlights in the development of phage as a potential therapeutic agent for bacterial infections}

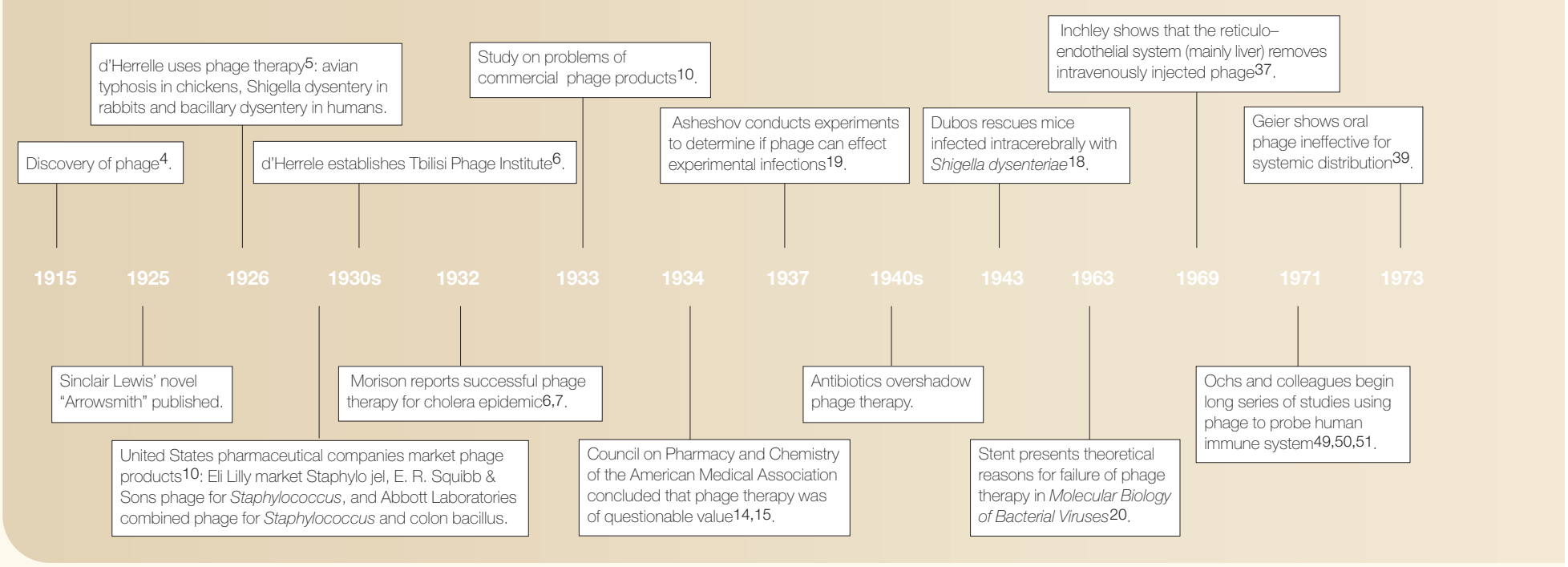


vectors for targeted gene delivery in mammalian cells ${ }^{44}$, there is evidence that in the natural setting such effects are normally minimal: phages are, for example, associated with bacteria in our colon, nose, throat and skin throughout our life span.

For nearly all pharmacological agents, information on drug distribution and clearance would be sufficient for pharmacokinetic studies. However, unlike most pharmaceuticals, phage can replicate exponentially. The exploitation of phage as antibacterial therapeutics requires knowledge of three dynamic components: the infected human, the infecting bacteria and the phage, and their complex interactions. Of these three dynamic components, two of them - the bacteria and the phage - are capable of exponential growth during the course of an infection and its treatment. Given this situation, it is crucial to ensure that the phage titres employed are sufficient for a successful therapeutic outcome (FIG. 3). To explore such parameters, Smith and Huggins used two experimental models, one in which mice were infected intracerebrally with E. coli $\mathrm{K} 1$ and another in which they were infected intramuscularly. Phage was administered intramuscularly in both of these studies. The phage levels were found to be highest in the infected tissues and they fell as the bacterial levels in the infected tissue decreased.

These results corroborated the earlier finding of Dubos et al. ${ }^{18}$ that mice infected intracerebrally with Shigella dysenteriae were rescued by administering phage into the peritoneal cavity ${ }^{45}$. In these experiments, the survival of untreated animals was $3.6 \%$, whereas the survival of phage-treated animals was $72 \%$. In addition, phage levels were observed to increase at the site of the infection - the brain - whereas the blood levels of phage seemed to be a "reflection of the events occurring in the brain". In uninfected control animals injected with phage, phage levels in the blood were compatible with the dilution of the phage in the total blood volume of the mouse. These researchers also showed that heat-inactivated phage provided no protective effects unless given days before the bacterial infection, and suggested that the protective effect of such heat-inactivated phage might result from the activation of antibacterial immunity by bacterial products present in the phage LYSATE.

Levin and Bull ${ }^{46}$, and Payne and Jansen ${ }^{47}$, have developed formal mathematical models on the basis of data from the Smith and Huggins $^{26}$ study. The Payne and Jansen ${ }^{47}$ model included terms for the loss of phage resulting from interaction with mammalian systems, such as the RES. Their analysis with this model corroborated the suggestion by Alinsky et al. ${ }^{8}$ that antibiotic and phage therapies might not be synergistic. Although such models are important for pharmacological planning, present efforts are based on limited datasets. Recently developed methods of visualizing bacterial infections in live animals using bioluminescent strains of bacteria might help in such pharmacokinetic studies ${ }^{48}$. This method uses a high sensitivity chargecoupled device camera to monitor bacteria in live mice. The bacteria are made bioluminescent by incorporating a luciferase transposon cassette into their genome. As it is feasible to incorporate luciferase transposon cassettes into phage genomes, it should also be possible to follow phage interactions with bacterial infections in vivo.

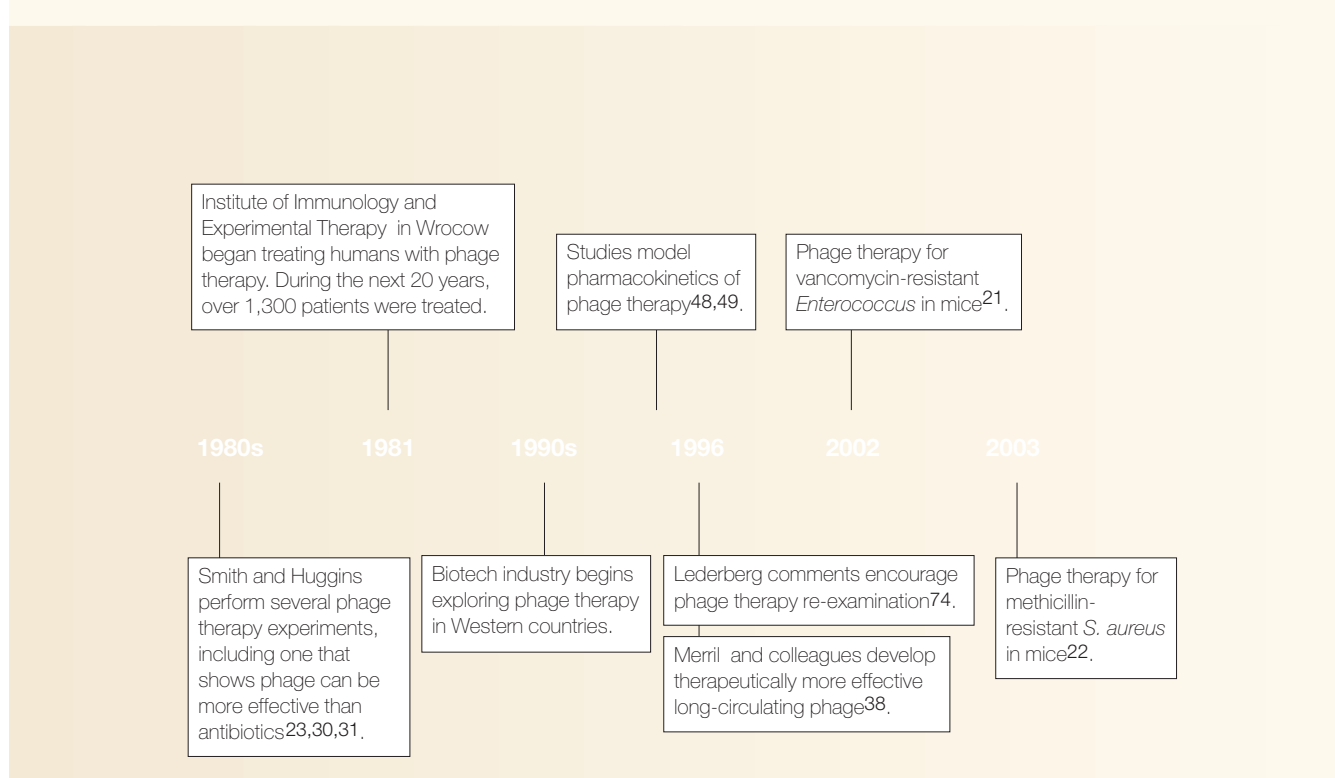

\section{Phage immunogenicity}

Phage immunogenicity is important for two reasons: first, because of potential adverse reactions, such as anaphylactic shock, and second, because of its effects on the pharmacokinetics of phage therapy. When phage are first used, some behave as NEO-ANTIGENS, as there are no pre-existing antibodies for these phage. This feature, along with the lack of apparent side effects, has permitted the use of phage $\phi \mathrm{X} 174$ as a probe of human and animal immune sytems ${ }^{49-51}$. Despite the apparent lack of antibodies to phage that present as neo-antigens they still interact with the innate immune system, as demonstrated by the rapid loss of phage injected into the circulatory system of germ-free mice $^{34}$ and the capacity of the liver to phagocytose more than $99 \%$ of administered phage within 30 minutes of inoculation ${ }^{37}$. It is important to note that not all phage present as neo-antigens, as KucharewicaKrukowska and Slopek noted in a study in which $11 \%$ of their healthy controls and $23 \%$ of their patients had antibodies against a Staphylococcus phage strain before administration of phage therapy ${ }^{45}$.

If a particular phage strain were used repeatedly as an therapeutic antibacterial agent, in addition to the interactions with the innate immune system, the adaptive immune system would be stimulated and result in the production of antibodies. Such activation of the adaptive immune system relies on somatic mutations and clonal expansion of $\mathrm{T}$ and $\mathrm{B}$ cells, which can take at least three to five days. In normal individuals injected with the highly immunogenic phage $\phi X 174$, the phage is normally cleared within three days and a primary immunoglobulin $\mathrm{M}$ ( $\mathrm{IgM}$ ) response can be observed that peaks two weeks after the initial injection or immunization. If another injection is made six weeks later, the IgM and IgG antibody titres increase and peak within one week of the second injection; subsequent phage injections result in further increases in the IgG titres ${ }^{50}$. Patients with severe combined immune deficiency (SCID), which is characterized by the absence of both $\mathrm{B}$ and $\mathrm{T}$ cell functions, display a prolonged period for the clearance of phage, with phage present up to four to six weeks after the initial injection. In addition, SCID patients do not develop detectable antibody responses to phage, even after repeated injections. Ochs and his colleagues have also found that although $\phi X 174$ phage is a potent antigen, it causes no recognized toxic effects in $\operatorname{man}^{49,52}$.

Similar findings were reported for the phage ENB6 used to treat mice infected with vancomycin-resistant Enterococcus ${ }^{21}$. 


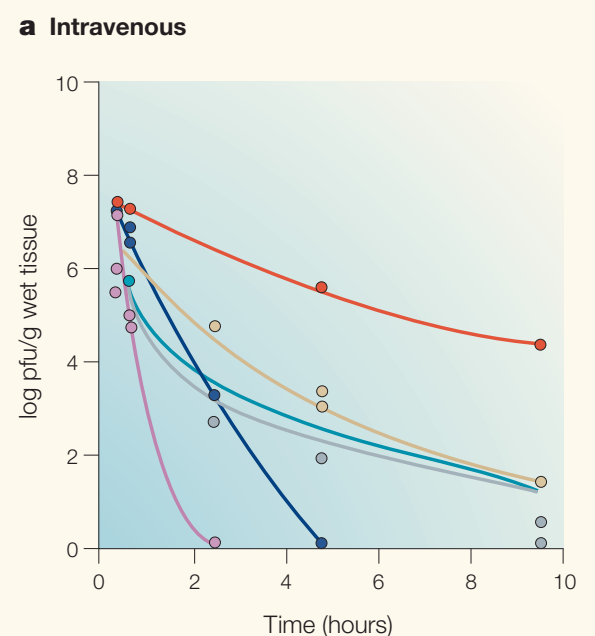

b Oral

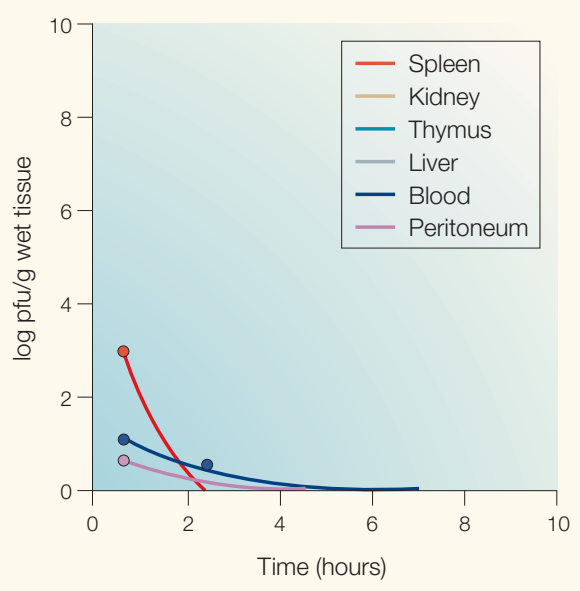

Figure 2 | Systemic distribution of phage following intravenous and oral administration of phage. These experiments demonstrate that oral administration is not an effective method for the delivery of phage to systemic sites as the blood and tissues levels were seven to eight orders of magnitude lower with oral administration than those achieved by systemic administration of phage. pfu, plaque-forming units.

To determine the immunogenicity of this phage, mice were given monthly injections. After the third in a series of five monthly injections, the titres of $\operatorname{IgG}$ and $\operatorname{IgM}$ increased 3,800-fold and fivefold, respectively, above background. The IgG levels did not change substantially after the third phage injection. No anaphylactic reactions, changes in core body temperature or other adverse events were observed in the mice over the course of these multiple injections of phage $^{21}$. It might be possible to develop phage that are less antigenic by using phagedisplaying peptide libraries or affinity matrixes made up of antibodies from human serum. This type of approach has been initiated to decrease the immunogenicity of therapeutically important enzymes ${ }^{53}$.

\section{Bacterial host specificity of phage}

The bacterial host range of phage is generally narrower than that found in the antibiotics that have been selected for clinical applications. Most phage are specific for one species of bacteria and many are only able to lyse specific strains within a species. This limited host range can be advantageous, in principle, as phage therapy should result in less harm to the normal body flora and ecology than commonly used antibiotics, which often disrupt the normal gastrointestinal flora and result in opportunistic secondary infections by organisms such as C. difficile $e^{54}$. The potential clinical disadvantages associated with the narrow host range of most phage strains can be addressed through the development of a large collection of well-characterized phage for a broad range of pathogens, and methods to rapidly determine which of the phage strains in the collection will be effective for any given infection.

Ideally, broad-host-range phage should be selected for therapeutic applications. However, if such phage strains cannot be found, present molecular techniques can be used to enhance the host range of some phage strains. For example, it has been found that coliphage K1-5 is a 'dual' specificity phage that encodes two different tail proteins; this allows it to attack and replicate in both $\mathrm{K} 1$ and $\mathrm{K} 5$ strains of E. coli $^{55}$. One tail protein found on phage K1-5 is a lyase protein, similar to that of phage K5 (specific for the K5 polysaccharide capsule), and a second tail protein found on this phage is an ENDOSIALIDASE similar to a tail protein found in phage $\mathrm{K} 1 \mathrm{E}$ (specific for the $\mathrm{K} 1$ polysaccharide capsule). In addition, the genomic region encoding these proteins is almost identical to the genomic construct found in the salmonella phage SP6, which codes for a protein that binds to the salmonella $\mathrm{O}$-antigen ${ }^{56}$. The observation of a similar tail genome motif in both the salmonella phage SP6 and the coliphages K1E, K5 and K1-5 indicates that this genomic construct might serve in the development of a modular phage platform that could operate over a wide bacterial host range.

Other mechanisms have been found that permit expansion of the bacterial host range of phage. These include the site-specific recombination systems that permit phage to switch between alternative tail fibre proteins ${ }^{57}$ and the use of a reverse transcriptase, possessed by a Bordetella phage, to generate variation in its tail fibre proteins ${ }^{58}$. Such expanded host-range 'platform' phage would provide for versatility and save time and effort compared with that required for the development of completely new phages for each bacterial strain.

Other factors can affect host specificity. For example, bacterial restriction/modification systems might limit the host range of some phage. This problem could be addressed, in principle, by engineering phages with genomes that do not contain restriction sites recognized by the non-permissive host. Alternatively, phages could be produced in bacterial strains that provide DNA modification(s) that allow the phage to escape restriction in the targeted strain of bacteria. Another approach would be to

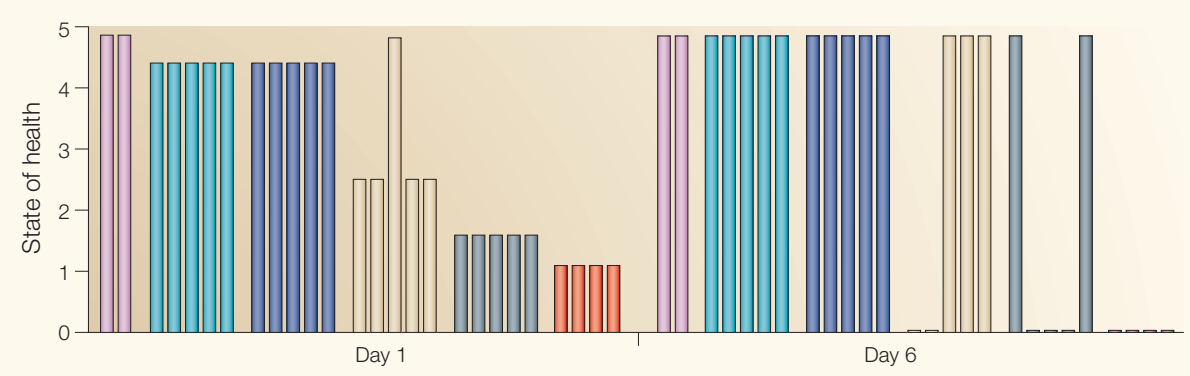

$\square$ Control mice $\quad \square 3 \times 10^{9} \mathrm{pfu} \quad \square 3 \times 10^{8} \mathrm{pfu} \quad \square 3 \times 10^{6} \mathrm{pfu} \quad \square 3 \times 10^{4} \mathrm{pfu} \quad \square$ No phage therapy

Figure 3 | The effect of therapeutic phage concentration on morbidity and mortality. When phage are used to treat a systemic bacterial infection, the concentration of phage administered must be adequate to kill the infecting bacteria before they can kill the mammalian host. This point is illustrated in the data, from a study using phage to treat bacteraemic mice infected with $10^{\circ}$ colony-forming units (cfu) of vancomycinresistant Enterococcus faecium ${ }^{21}$. This concentration of bacteria normally results in death within 48 hours. Each bar represents a single mouse, and all but the two control mice (injected with buffer rather than bacteria, represented by the pink bars) were infected with $10^{\circ} \mathrm{cfu}$ of bacteria. The phage concentrations administered 45 minutes after the bacterial infection are depicted in the key. The mice in the last group (red bars) did not receive phage therapy. The state of health scale is a non-parametric scale in which: $5=$ normal; 4 = decreased activity and ruffled fur; 3 = lethargy, rufled fur and hunchback posture; 2 = hunchback posture and partially closed eyes with exudates; $1=$ moribund; and $0=$ death. pfu, plaque-forming units. 
incorporate genes into the phage genome that facilitate inhibition of bacterial restriction/modification enzymes, as exemplified by the mechanism used by the phage T7 which encodes an antirestriction enzyme ${ }^{59}$. A construct containing such an antirestriction gene might be adapted for use in other phage strains, or it might be possible to modify T7 phage to expand its bacterial host range for E. coli infections.

\section{Phage growth: in vitro versus in vivo} In addition to the factors addressed above, bacteria grown with standard laboratory protocols can behave differently in the milieu of an infection. Bacteria possess feedback mechanisms that can alter their gene expression in response to changing environmental conditions. Such variations in gene expression can affect phage susceptibility. For example, Karakawa noted that $S$. aureus rarely expresses the capsular polysaccharides found in clinical isolates when the bacteria are grown in the laboratory ${ }^{60}$. Given the possibility for such changes in the bacterial capsule, phage discovered using bacteria grown in vitro might not be able to multiply in an infected animal. Recently, it has been reported that phage that infected certain strains of E. coli that did not express the cell surface protein Ag43 in standard laboratory growth media can be inhibited by concentrations of bile salts similar to that found in the gastrointestinal tract ${ }^{61}$. In this case, the bile salts might affect the expression of the Ag43 protein, which has been shown to be a phase variable protein whose expression is associated with E. coli BIOFILM formation ${ }^{62}$.
In addition, different in vitro and in vivo bacterial densities can be important ${ }^{47}$. Variations in phage physiology also are important, as some phage infections cause the host bacteria to release lysins that result in the destruction of bacteria not directly infected by the phage (BOX 1 and FIG. 4). In the early phage literature, there are reports of body fluids (for example, serum, pus, ascites fluids, cerebrospinal fluid, urine and bile) that inhibit the infectivity of phage that were active in vitro against typhoid, colon bacilli and staphylococci ${ }^{63,64}$. Some of these effects might have resulted from alterations of bacterial physiology.

\section{Detrimental phage genes}

Some phage strains, the lytic phage, kill bacteria, whereas others - LYSOGENIC or temperate phage - have a dual life style: they can either kill and lyse their bacterial host or become quiescent by integrating their genome into their bacterial host chromosome. Some lysogenic phage encode toxins or factors that enhance bacterial pathogenesis (TABLE 1). Phage can also contribute, through transduction, to the transmission of antibiotic-resistance genes $^{65}$. It is essential that phage considered for therapeutic applications be screened for toxin genes, either biochemically or by sequencing their DNA. The presence of toxin, antibiotic resistance genes, and genes that increase bacterial pathenogenicity, can be checked by searching phage genomes against GenBank online using the Basic Local Alignment Search Tool (BLAST) ${ }^{66}$ and other similar programs. Success cannot be assumed as we are still in the discovery stage of such detrimental

\section{Box 1 | Therapeutic use of phage products}

Phage gene products might also serve as therapeutic agents. Although such applications lack the exponential growth capacity of phage, they could still be highly effective. For example, the smallgenome phages $\phi \mathrm{X} 174$ and $\mathrm{Q} \beta$ encode polypeptides that could be developed into a new class of antibiotics, as they interfere with bacterial cell wall biosynthesis ${ }^{79}$. Such inhibition results in bacterial lysis. Similarly, phage-encoded endolysins that disrupt the peptidoglycan matrix of the bacterial cell wall, and phage-encoded holins that permeabilize bacterial membranes, can also serve as effective antibacterial agents. A phage lysin, specific for streptococci groups A, C and E, has been used to treat experimental upper respiratory infections in mice ${ }^{80}$. Such lysins should be less disruptive than most antibiotic treatments as they have little, if any, effect on other commensal organisms in the oral and upper respiratory tract. In another example, the $\gamma$ phage of Bacillus anthracis encodes a lysin that proved to be effective in rescuing mice infected with Bacillus cereus, a bacterial strain closely related to $B$. anthracis ${ }^{69}$. No resistant $B$. cereus strains were detected following such treatment. In addition, phage lysin genes have been incorporated into bacterial genomes for prophylactic applications. Gaeng et al. ${ }^{81}$ developed such a bacterial strain to secrete the functional phage lysin enzymes Ply511 and Ply118 to reduce Listeria monocytogenes contamination in dairy cheese production starter cultures ${ }^{81}$. These phage lysins can also be used diagnostically. For example, when PlyG lysin destroys B. anthracis, ATP is released, which, in conjunction with the luciferin/luciferase system, results in the emission of light that can also be used to rapidly detect bacilli and their germinating spores. This system was able to detect as few as 100 spores $^{69}$.

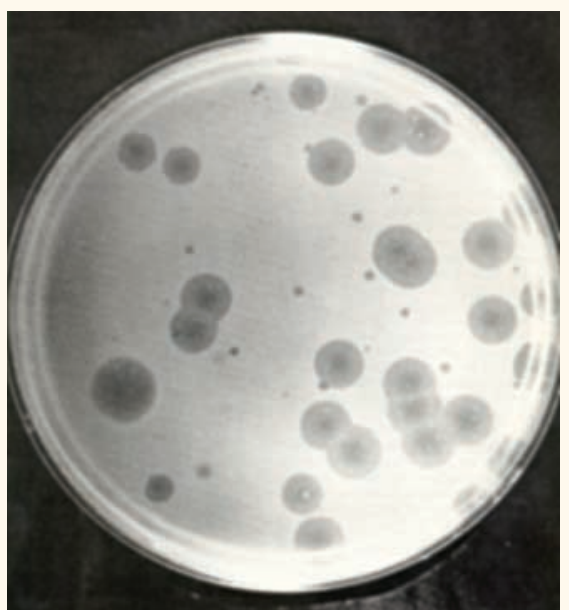

Figure 4 | Phage plaques on a bacterial 'lawn'. The PHAGE PLAQUES illustrated on this plate display a mixture of morphologies, which reflect the different phage strains applied to this bacterial plate. Some of the phage produce small clear plaques, whereas other phage strains that produce lysins have a clear centre zone surrounded by a spreading zone of killing.

genes. The usefulness of bioinformatic analysis will increase as knowledge of these potential deleterious genes accumulates.

\section{Selection of therapeutic phage strains} The narrow host range of most phage strains dictates the need for the rapid determination of bacterial susceptibility. The determination of suitable therapeutic phage strain(s) using traditional procedures can take days to accomplish, limiting the use of phage therapy to slowly progressing infections. However, recent methods have been developed that permit the identification of both the infectious agent and a suitable phage strain within a day or less.

One such approach uses of phage that contain reporter genes, such as luciferase ${ }^{67,68}$. For example, a collection of phage strains, each encoding luciferase protein, could be individually placed in a multi-well plate. When a clinical sample, such as urine or sputum, is added to the wells, light will be emitted and detected in those wells that contain a phage strain that successfully infects the bacteria in the clinical specimen. Such light emission would serve to identify both bacterial strains and the phage strains that could be used against them. This test could be performed in hours, instead of the days that traditional culture methods require. This approach has been used to detect Listeria contamination in foods $s^{67}$ and in an inexpensive and rapid diagnostic test for tuberculosis ${ }^{68}$. Alternatively, similar results can be achieved by using phage that do not have such marker genes, by placing luciferin and luciferase in 


\begin{tabular}{|c|c|c|c|}
\hline Phage & Gene & Gene product/phenotype & Bacterial host \\
\hline $\begin{array}{l}933, \mathrm{H}-19 \mathrm{~B} \\
\Phi \mathrm{FC} 3208 \\
\lambda \\
\lambda\end{array}$ & $\begin{array}{l}\text { stx } \\
\text { hly2 } \\
\text { lom } \\
\text { bor }\end{array}$ & $\begin{array}{l}\text { Shiga toxins } \\
\text { Enterohaemolysin } \\
\text { Serum resistance } \\
\text { Host-cell envelope protein }\end{array}$ & $\begin{array}{l}\text { Escherichia coli } \\
\text { O157:H7 }\end{array}$ \\
\hline $\begin{array}{l}\text { Sfi6 } \\
\text { sfll,sfV,sfX }\end{array}$ & $\begin{array}{l}\text { oac } \\
\text { gtrll }\end{array}$ & $\begin{array}{l}\text { O-antigen acetylase } \\
\text { Glucosyl transferase }\end{array}$ & Shigella flexneri \\
\hline $\begin{array}{l}\text { SopE } \Phi \\
\text { Gifsy-2 } \\
\text { Gifsy-2 } \\
\text { Gifsy-1 } \\
\varepsilon^{34}\end{array}$ & $\begin{array}{l}\text { sopE } \\
\text { sodC-1 } \\
\text { nanH } \\
\text { gipA } \\
\text { rfb }\end{array}$ & $\begin{array}{l}\text { Type III effector } \\
\text { Superoxide dismutase } \\
\text { Neuraminidase } \\
\text { Insertion element } \\
\text { Glucosylation }\end{array}$ & Salmonella enterica \\
\hline $\begin{array}{l}\text { CTX } \Phi \\
\text { K139 } \\
\text { VPI } \Phi\end{array}$ & $\begin{array}{l}\text { ctxAB } \\
\text { glo } \\
\text { tcp }\end{array}$ & $\begin{array}{l}\text { Cholera toxin } \\
\text { G-protein like } \\
\text { Toxin co-regulated pilus }\end{array}$ & Vibrio cholera \\
\hline ФСТХ & $c t x$ & Cytotoxin & Pseudomonas aeruginosa \\
\hline C1 & C1 & Neurotoxin & Clostridium botulinum \\
\hline $\begin{array}{l}\text { NA } \\
\text { \$13 } \\
\text { TSST-1 }\end{array}$ & $\begin{array}{l}\text { see, sel } \\
\text { entA, sak } \\
\text { tst }\end{array}$ & $\begin{array}{l}\text { Enterotoxin } \\
\text { Enterotoxin A, staphylokinase } \\
\text { Toxic shock syndrome-1 }\end{array}$ & Staphylococcus aureus \\
\hline $\mathrm{T} 12$ & speA & Erythrogenic toxin & Streptococcus pyogenes \\
\hline$\beta$-phage & tox & Diptheria toxin & Corynebacterium diptheriae \\
\hline
\end{tabular}

the phage/bacterial incubation mixture in each of the wells of the multi-well plate. The lysis of bacterial strains by a phage strain in any of the wells will result in the discharge of adenylate kinase into the well, which will convert the ADP in the reaction mix to ATP. As the luciferin/luciferase system can utilize the ATP for light emission, lysis will serve to identify phage susceptibility without the need to genetically engineer the phage with a luciferase reporter gene ${ }^{69}$.

Another method for the rapid identification of bacterial strains could be provided by mass spectrometry (MS). Mass fragment 'fingerprints' of lipid, protein and nucleic acid bacterial components are used at present for rapid strain identification ${ }^{70,71}$. It might also be possible to use this approach to determine whether bacteria are susceptible to a particular phage strain. However, such information is not available at present and it might be impractical to gain sufficient knowledge of bacterial mass fingerprints to determine which phage strains to use therapeutically for a bacterial host responsible for an infectious disease. Alternatively, phage gene products might provide for the development of markers for both bacterial identification and as an indicator of phage susceptibility. In this approach, one could use MS by placing a clinical sample in growth media to amplify the infecting bacteria followed by exposure to selected 'therapeutic' phage strains. If the bacteria were susceptible to the phage, MS would detect signature fragments of phage proteins that are expressed only when infection of the bacteria occurs by a specific phage. Such 'signature' fragments, that are not part of the phage virion, would be generated from phage: RNA polymerase, regulatory protein or lytic enzymes.

DNA microarray technologies also offer possibilities for determining bacterial strains in disease states and possibly the phage strains that might be used therapeutically. DNA microarrays, in conjunction with polymerase chain reaction, are now being developed for the rapid diagnosis of bacterial strains and antibiotic susceptibility ${ }^{72}$. In principle, it might be possible to develop such methods for the determination of bacterial strains and their phage susceptibility.

\section{Box 2 | Therapeutic failure that might have resulted from impure phage}

Some of the early clinical therapeutic failures might have been due to inadequate purification of the phage preparations. In one such example, reported in 1932, a phage strain was found that seemed to be promising as a therapeutic agent as it could lyse cultures of plague (Yersinia pestis) grown in broth media in less than 2 hours. However, when this phage strain, purified solely by filtration, was injected into rabbits experimentally infected with Y.pestis, the mortality increased to levels above those found in infected rabbits that were not treated with phage. Furthermore, when this phage preparation was used to treat 33 human patients, they all died. The mortality from plague is normally $60-90 \%{ }^{82}$.

\section{Development and preparation of phage} In addition to biological factors, phage preparative methods are crucial for the development of reliable phage therapeutics. Early therapeutic applications used impure phage preparations with deleterious clinical effects (BOX 2). Contamination of phage preparations can result in increased morbidity or, in some cases, mortality. For example, in a recently published study, intraperitoneal inoculation of mice with filter-sterilized phage lysates produced reactions associated with endotoxin levels that ranged from mild (ruffled fur) to death $^{38}$. Adequate purification, for example, by physical and/or biochemical methods, must be adopted for the production of toxinfree, clinical-grade phage preparations with long-term storage stability ${ }^{38,73}$. Phage prepared in this manner have been administered to animals without any noticeable ill effects and Ochs et al. have used such purified phage in their human protocols ${ }^{49}$.

In developing phage purification procedures, testing for adverse effects should not be limited to observation with healthy animals. Individuals that are under stress can have a lowered tolerance to endo- and exotoxins. In a recent mouse bacteraemia study, a lower survival rate was observed in a 'control experiment' in which a phage strain, known to be inactive against the bacterial strain being used at the $\mathrm{LD}_{50}$ level, was administered to the infected mice. Although the highest doses of this phage preparation produced no apparent adverse effects in healthy uninfected animals, an increased mortality was observed in the bacteraemiastressed mice. This increased mortality was phage-dose dependent, indicating that stressed animals are more sensitive to the phage itself, or to the trace amounts of endo- and exotoxins present in the phage preparations, than normal animals ${ }^{21}$. This example provides additional evidence for the need for highly purified phage preparations for therapeutic applications.

It should also be noted that bacteriostatic or bacteriocidal agents, used to ensure that no active bacteria are present in phage preparations, can also be detrimental. The association between 'weak' phage preparations and the presence of organomercury compounds was made in a 1932 study of commercial phage preparations from a large US pharmaceutical company ${ }^{10}$.

\section{Future prospects}

Although results from animal experiments are encouraging, continuing research will be needed to develop phage therapy for the treatment of human infectious diseases. These 


\section{Glossary}

ADAPTIVE IMMUNE SYSTEM

The arm of the immune system that mounts an antigenspecific immune response as the result of the clonal selection of antigen-specific lymphocytes. Such lymphocytes produce antibodies that react with the antigen. The adaptive immune responses differ from the innate and nonadaptive immune system, which does not depend on clonal selection of antigen-specific lymphocytes.

BIOFILM

A structure made up of a community of bacteria composed of microcolonies and water channels that survives at a liquid interface. Such biofilms play a role in the pathogenic effects of bacterial infections associated with gingivitis, colitis, vaginitis, urethritis, conjunctivitis and otitis.

ENDOTOXINS

Components of bacterial cells that are usually associated with the lipopolysaccharide components of the outer

layer of Gram-negative bacterial cell walls that are toxic (to mammals). Endotoxins are released in large quantities upon lysis of Gram-negative bacterial cells.

\section{ENDOSIALIDASES}

Enzymes that cleave at the sialic acid residue sites of the complex oligosaccharides associated with the protective capsule of many bacterial strains.

EXOTOXINS

A broad class of factors released by pathogenic bacteria that can harm infected mammals. Examples of such exotoxins are botulism toxin (Clostridium botulinum), streptolysins (Streptococcus pyogenes) and diphtheria toxin (Corynebacterium diptheriae).

\section{IATROGENIC}

An effect that is induced in a patient by a physician's activity or therapy; such effects often occur as complications of treatments for infectious diseases.

$\mathrm{LD}_{50}$

The amount of a substance that causes the death of $50 \%$ of test subjects.

efforts should include studies of phage genomics, pharmacokinetics and efficacy in animal models of infectious diseases. In addition, phage chosen for therapeutic applications will need to be screened to reduce the chance that they carry genes encoding toxins, or factors that enhance bacterial pathogenicity. Phage growth, purification and storage protocols are needed to assure therapeutic efficacy and to reduce the possibility of contamination of pharmaceutical preparations by toxins and bacterial debris. Furthermore, the narrow host range of most phage strains requires the development of rapid methods for the determination of appropriate phage strains for use in specific infections.

Development of therapeutic phage could provide some relief from the growing threat from the emerging antibiotic-resistant bacterial strains and, as Lederberg suggested, treatments for epidemics such as cholera in refugee camps ${ }^{74}$. In addition, the narrow host
LYSATE

The colloidal bacterial growth media remaining after phage replicate and kill the host cells. Lysates contain phage progeny, bacterial cell wall debris and, often, internal cellular components (for example, proteins, nucleic acids, small molecules and so on).

\section{LYSOGENIC PHAGE}

Phage that are capable of integrating their genome (that is, lysogenize) into the host chromosome. Such phages often mediate horizontal gene transfer (transduction) between bacterial strains. Most lysogenic phage can also go through a lytic cycle to produce more phage, often after induction (from some environmental factor).

LYTIC PHAGE

Phage that infect bacterial cells to replicate and then lyse the bacterial host.

\section{NEO-ANTIGEN}

An antigen for which animals or humans being studied have no pre-existing antibodies. The phage $\phi \mathrm{X} 174$, which is highly immunogenic, has served as such a neo-antigen in studies of human antibody responses, as most humans have no pre-existing antibodies to this phage.

PHAG

Bacterial viruses. The term phage is used as both singular and plural when referring to phage(s) that is/are member(s) of a single phage strain. However, when referring to phage in more than one strain the plural is phages.

\section{PHAGE PLAQUE}

The lesion formed when a phage particle is applied to film of a susceptible bacterial strain that is growing on an agar surface. The lesion results from the infection of a bacterial cell by a phage particle, followed by the production of phage progeny and their release by lysis, followed by the infection and lysis of additional bacterial cells in the vicinity of the initial infection.

range of phage could be better suited than presently employed antibiotics to a number of clinical applications. For example, the lack of genetic variability in antibiotic-resistant bacteria suggests that the resulting pathogenic bacteria might offer ideal targets for phage therapy. Only 10 strains of Pneumococcus are associated with $75 \%$ of the cases of antibiotic-resistant childhood pneumonia, and one-half of these cases are caused by the single strain 'Spain 23-E'. Herminia de Lencastre obtained similar results in a study of methicillin-resistant S. aureus, in which only five strains of methicillin-resistant $S$. aureus were found in $70 \%$ of 3,000 clinical isolates from 14 countries $^{75}$. The narrow host range of phage should also reduce the disturbance of the complex bacterial ecological systems associated with the human gastrointestinal system. Applications of phage to treat infections could eliminate the IATROGENIC effects of antibiotics, such as the antibiotic-related diarrhoea diseases that range from 'nuisance' diarrhoea to colitis associated with C. difficile infection $s^{55}$.

Phage, with their narrow host range, could also prove useful in treating bacterial infections in agricultural applications without disturbing larger ecological systems, as is often the problem with antibiotics ${ }^{74}$. This suggestion is strengthened by the recent observations that many antibiotic-resistant bacterial strains are arising through clonal selection. In recognition of this growing problem, the FDA recently announced that it is re-evaluating livestock antibiotics, and it is now requiring manufacturers of proposed livestock antibiotics to determine whether these proposed antibiotics will be associated with the emergence of pathogenic organisms with resistance to drugs presently in use for the treatment of human diseases ${ }^{76}$.

In regard to concerns over regulatory agency approval, it should be noted that phage have been used successfully as a means to probe immune-deficiency diseases in human studies for the past three decades ${ }^{49,50}$. In addition, some vaccines were found, in the 1970 s, to be contaminated with phage. An executive order was issued to permit the continued use of these contaminated vaccines ${ }^{77,78}$. We should also recognize that we are normally in contact with phage throughout our lifetime, with the complex interactions of bacteria and phage in our colon, upper respiratory system and on our skin. In fact, many present phage collections were derived from human waste.

It is clear from recent experiments that phage therapy has the potential to rescue animals infected with antibiotic-resistant bacterial stains $^{22,21}$. We now also have much of the knowledge needed to develop phage into reliable therapeutic preparations. Whether we embark on efforts needed to develop therapeutic phage for human infections depends in part on our need to obtain relief from the growing threat of emerging antibiotic-resistant bacterial strains and our will to accomplish this task.

${ }^{\star}$ Section on Biochemical Genetics, National Institute of Mental Health, National Institutes of Health, Bethesda, Maryland 20892, USA. ${ }^{\ddagger}$ Section of Developmental Genetics, National Cancer Institute, National Institutes of Health, Bethesda, Maryland 20892, USA. e-mails: sadhya@helix.nih.gov, merrilc@helix.nih.gov,dscholl@helix.nih.gov. doi:10.1038/nrd1111

1. Thornsberry, C. et al. Regional trends in antimicrobial resistance among clinical isolates of Streptococcus pneumoni pneumoniae, Haemophilus influenzae and Moraxella catarhalls in the United States. results from the TRUST Surveillance Program, 1999-2000. Clin. Infect. Dis. 34
S4-S16 (2002). 


\section{PER S P E C T IVES}

2. National Center for Infectious Diseases. Campaign to prevent antimicrobial resistance in healthcare settings. Centers for Disease Control and Prevention [online] (cited 30 Sep 2002) <http://www. cdc. gov/drugresistance/ healthcare/problem $\mathrm{htm}>(2002)$

3. Hashimoto, H. Drug resistance of methicillin-resistant Staphylococcus aureus (MRSA) in Japan until 1993. Jpn J. Antibiot. 47, 575-584 (1994).

4. Twort, F. W. An investigation on the nature of ultramicroscopic viruses. Lancet 2, 1241-1243 (1915). This paper presents the original discovery of bacterial viruses.

5. d'Herelle, F. The Bacteriophage and its Behavior 490-541 (Williams \& Wilkins, Baltimore, Maryland, 1926). Although much of the material in this book is dated, it still contains observations of interest.

6. Summers, W. C. Felix d'Herelle and the origins of Molecular Biology 125-144 (Yale University Press, New Haven and London, 2001).

7. Summers, W. C. Bacteriophage therapy. Annu. Rev. Microbiol. 55, 437-451 (2001).

8. Alinsky, J., Iczkowski, K., Rapoport, A., \& Troitsky, N. Bacteriophages show promise as antimicrobial agents. J. Infect. 16, 5-15 (1998). This and the following article present an overall review of phage therapy efforts in Poland and the Soviet Union.

9. Sulakvelidze, A., Alavidze, Z. \& Morris, J. G. Jr Bacteriophage therapy. Antimicrob. Agents Chemother. 45, 649-659 (2001).

10. Straub, M. E. \& Applebaum, M. Studies on commercia bacteriophage products. JAMA 100, 110-113 (1933). Insights into the problems associated with pharmaceutical phage preparations.

11. Larkum, N. W. Bacteriophage in clinical medicine. J. Lab. Clin. Med. 17, 675-680 (1932)

12. Van Helvoort, T. Bacteriological and physiological research styles in the early controversy on the nature of the bacteriophage phenomenon. Med. Hist. 36, 234-270 (1992).

13. Randall-Hazelbauer, L. \& Schwartz, M. Isolation of the bacteriophage $\lambda$ receptor from Escherichia coli. J. Bacteriol. 116, 1436-1446 (1973).

14. Eaton, M. D. \& Bayne-Jones, S. Bacteriophage therapy JAMA 103, 1769-1776, 1847-1853 \& 1934-1939 (1934)

5. Ho, K. Bacteriophage therapy for bacterial infections Perspect. Biol. Med. 44, 1-16 (2001)

16. Barrow, P. A. \& Soothill, J. S. Bacteriophage therapy and prophylaxis: rediscovery and renewed assessment of potential. Trends Microbiol. 5, 268-271 (1997)

17. Evans, A. C. Inactivation of antistreptococcus bacteriophage by animal fluids. Public Health Rep. $\mathbf{4 8}$, 411-426 (1933).

18. Dubos, R. J., Straus, J. H. \& Pierce, C. The multiplication of bacteriophage in vivo and its protective effects against experimental infection with Shigella dysenteria. J. Exp. Med. 20, 161-168 (1943).

This paper presents crucial experiments designed to explore the mechanisms underlying the therapeutic effects observed when using phage to treat a systemic bacterial infection.

19. Asheshov, I. N., Wilson, J. \& Topley, W. W. C. The effect of an anti-vi bacteriophage on typhoid infection in mice. Lancet 319-320 (1937).

20. Stent, G. S. Molecular Biology of Bacterial Viruses W. H. Freeman, San Francisco, 1963). Essential information for those interested in phag and their applications, and provides insights into theories concerning phage therapy failures.

21. Biswas, B. et al. Bacteriophage therapy rescues mice bacteremic from a clinical isolate of vancomycinresistant Enterococcus faecium. Infect. Immun. $\mathbf{7 0}$ 204-210 (2002).

In addition to a demonstration of the effectiveness of phage therapy for treatment of animals infected with antibiotic resistant bacteria, the experiments in this study also show that the rescue of infected animals is directly dependent on phage function.

22. Matsuzaki,S. et al. Experimental protection of mice . Matsuzaki,S. et al. Experimental protection of mice against lethal Staphylococcus aureus infection by nove
bacteriophage MR11. J. Infect. Dis. 187, 613-624 (2003)

The animal experiments described in this paper provide evidence that phage could provide an alternate therapeutic approach for the treatment of a serious antibiotic-resistant bacterial infection.

23. Soothill, J. S. Treatment of experimental infections of mice with bacteriophages. J. Med. Microbiol. 37 , 258-262 (1992).
24. Cerveny, K. E, Depaola, A., Duckworth, D. H \& Gulig, P. A. Phage therapy of local and systemic disease caused by Vibrio vulnificus in iron-dextran-treated mice. Infect. Immun. 70, 6251-6262 (2002).

25. Broxmeyer, L. et al. Killing of Mycobacterium avium and Mycobacterium tuberculosis by a mycobacteriophage delivered by a nonvirulent mycobacterium: a model for phage therapy of intracellular bacterial pathogens. phage therapy of intracellular bacteria Intracellular bacterial infections are often difficult Intracellular bacterial infections are often difficult
to treat and this paper provides evidence that phage could provide a therapeutic approach to this problem.

26. Smith, H. W. \& Huggins, M. B. Successful treatment of experimental $E$. coli infections in mice using phage: its general superiority over antibiotics. J. Gen. Microbiol. 128, 307-318 (1982)

This is a crucial study in which fewer resistant bacterial colonies were found following phage therapy than found following antibiotic therapies, therapy than found following antibiotic therapies, reported to have alterations in their capsules reported to have alterations in their capsules

27. Smith, H. W., Huggins, M. B. \& Shaw, K. M. The control of experimental $E$. coli diarrhea in calves by means of bacteriophages. J. Gen. Microbiol. 133, 1111-1126 (1987)

28. Smith, H. W., Huggins, M. B. \& Shaw, K. M. Factors influencing the survival and multiplication of bacteriophages in calves and their environments. J. Gen. Microbiol. 133, 1127-1135 (1987).

29. Ramesh, V., Fralick, J. A. \& Rolfe, R. D. Prevention of Clostridium difficile-induced ileocecitis with bacteriophage. Anaerobe 5, 69-78 (1999).

30. Soothill, J. S. Bacteriophage prevents destruction of skin grafts by Pseudomonas aeruginosa. Burns $\mathbf{2 0}$ 209-211 (1994).

31. Nakai, T. \& Park, S. C. Bacteriophage therapy for infectious diseases in aquiculture. Res. Microbiol. 153, 13-18 (2002).

32. Flaherty, J. E., Harbaugh, B. K., Jones, J. B., Somodi, G. C. \& Jackson, L. E. H-mutant bacteriophages as a potential biocontrol of bacterial blight of geraniums. Hortscience 36, 90-100 (2001).

33. Flaherty, J. E., Jones J. B., Harbaugh, B. K., Somodi, G. C. \& Jackson, L. E. Control of bacterial spot on tomato in the greenhouse and field with $\mathrm{H}$-mutant bacteriophages Hortscience 35, 882-884 (2000).

34. Geier, M. R., Trigg, M. E. \& Merril, C. R. The fate of bacteriophage $\lambda$ in non-immune germ-free mice. Nature 246, 221-223 (1973).

This paper highlights the distribution of functional phage administered by various routes in mice and it presents evidence that oral administration is an ineffective method for achieving a systemic distribution of phage.

35. Appelmans, R. Le bacteriophage dans l'organisme. Comp. Rend. Soc. de Biol. (Paris) 85, 722-724 (1921).

36. Nungester, W. J. \& Watrous, R. M. Accumulation of bacteriophage in spleen and liver following its intravenous inoculation. Proc. Soc. Exper. Biol. Med. 31, 901-905 (1934).

37. Inchley, C. J. The activity of mouse kupffer cells following intravenous injection of T4 bacteriophage. Clin. Exp. Immunol. 5, 173-187 (1969).

The crucial role of the liver in removing phage from the circulation of mammals is clearly delineated in this study.

38. Merril, C. R. et al. Long-circulating bacteriophage as antibacterial agents. Proc. Natl Acad. Sci. USA 93 3188-3192 (1996).

This paper describes the development of a selection technique, based on the recognition that the efficacy of phage therapy might be impaired by the mammalian innate immune system, for obtaining long-circulating phage with enhanced therapeutic properties.

39. Doerfler, W. et al. On the insertion of foreign DNA into mammalian genomes: mechanism and consequences. Gene 157, 241-245 (1995).

40. Schubbert, R., Hohlweg, U., Renz, D. \& Doerfler, W. On the fate of orally ingested foreign DNA in mice: chromosomal association and placental transmission to the fetus. Mol. Gen. Genet. 259, 569-576 (1998).

41. Schubbert, R., Renz, D., Schmitz, B. \& Doerfler, W. Foreign (M13) DNA ingested by mice reaches periphera leukocytes, spleen, and liver via the intestinal wall mucosa and can be covalently linked to mouse DNA. Proc. Natl Acad. Sci. USA 94, 961-966 (1997).

42. Merril, C. R., Geier, M. R. \& Petricciani, J. C. Bacterial virus gene expression in human cells. Nature $\mathbf{2 3 3}$ 398-400 (1971).
43. Horst, J., Kluge, F., Beyreuther, K. \& Gerok, W. Gene transfer to human cells: transducing phage $\lambda$ plac gene expression in GM1-gangliosidosis fibroblasts. Proc. Nat Acad. Sci. USA 72, 3531-3535 (1975).

44. Larocca, D. et al. Evolving phage vectors for cell targeted gene delivery. Curr. Pharm. Biotechnol. 3, 45-57 (2002).

45. Kucharewica-Krukowska A. \& Slopek S. Immunogenic effect of bacteriophage in patients subjected to phage therapy. Arch Immunol. Ther. Exp. Warsz.) 35, 553-561 (1987).

46. Levin, B. R. \& Bull, J. J. Phage therapy revisited: the population biology of a bacterial infection and its treatment with bacteriophage and antibiotics. Am. Nat. 147, 881-898 (1996).

47. Payne, R. J. H. \& Jansen, V. A. A. Pharmacokinetic principles of bacteriophage therapy. Clin. Pharmacokinet. 42, 315-325 (2003).

48. Francis, K. P. et al. Visualizing Pneumococcal infections in the lungs of live mice using bioluminescent Streptococcus pneumoniae transformed with a novel Gram-positive lux transposon. Infect. Immun. 69 3350-3358 (2001).

Visualization methods presented in this study could facilitate the study of bacterial infections and their treatment.

49. Ochs, H. D., Davis, S. D. \& Wedgwood, R. J. Immunologic responses to bacteriophage $\Phi \times 174$ in immunodeficiency diseases. J. Clin. Invest. 50, 2559-2568 (1971).

This paper presents some of the initial experiments using phage to probe the human and mammalian immune systems.

50. Ochs, H. D., Nonoyama, S., Zhu, Q., Farrington, M. \& Wedgwood, R. J. Regulation of antibody responses: the role of complement and adhesion molecules. Clin. Immunol. Immunopathol. 3, S33-S40 (1993).

51. Clark, L., Greenbaum, C., Jiang, J., Lernmark, Å. \& Ochs, $\mathrm{H}$. The antibody response to bacteriophage is linked to the lymphopenia gene in congenic BioBreeding rats. FEMS Immunol. Med. Microbiol. 32, 205-209 (2002).

52. Ching,Y-C., Davis, S. D. \& Wedgwood, R. J. Antibody studies in hypogammaglobulinemia. J. Clin. Invest. 45, 1593-1600 (1966)

53. Jenne, S., Brepoels, K., Collen, D. \& Jespers, L. High-resolution mapping of the $B$ cell epitopes of staphylokinase in humans using negative selection of a phage-displayed antigen library. J. Immunol. 161 3161-3168 (1998)

54. Bartlett, J. G. Antibiotic-associated diarrhea. N. Engl. J. Med. 346, 334-339 (2002)

55. Scholl, D., Rogers, S., Adhya, S. \& Merril, C. Bacteriophage K1-5 encodes two different tail fiber proteins allowing it to infect and replicate on both $\mathrm{K} 1$ and Adaptations of the phage construct presented in this paper could provide a general approach for the extension of the bacterial host range of phage.

56. Scholl, D., Adhya, S. \& Merril, C. R. Bacteriophage SP6 is closely related to phages K1-5, K5 and K1E but encodes a tail protein very similar to that of the distantly related P22. J. Bacteriol. 184, 2833-2836 (2002).

57. Sandmeier, H. Acquisition and rearrangement of sequence motifs in the evolution of bacteriophage tail fibres. Mol. Microbiol. 12, 343-350 (1994).

58. Liu, M. et al. Reverse transcriptase-mediated tropism switching in bordetella bacteriophage. Science $\mathbf{2 9 5}$ 2091-2094 (2002).

59. Moffatt, B. A. \& Studier, F. W. Entry of bacteriophage T7 DNA into the cell and escape from host restriction. J. Bacteriol. 170, 2095-2105 (1988).

60. Hollon, T. Impossible vaccine tames Staphylococcus aureus. The Scientist 16, 24-28 (2002).

61. Gabig, M. et al. The cell surface protein Ag43 facilitates phage infection of Escherichia coli in the presence of bile salts and carbohydrates. Microbiology 148, 1533-1542 (2002)

62. Danese, P. N., Pratt, L. A., Dove, S. L. \& Kolter, R. The outer membrane protein, antigen 43 , mediates cell-to-cell interactions within Escherichia coli biofilms. Mol. Microbiol. 37, 424-432 (2000).

63. Colvin, M. G. Behavior of bacteriophage in body fluids and in exudates. J. Infect. Dis. 51, 527-541 (1932).

64. Calalb, G. Action de la bile sur bacteriophage et importance de cette action. Compt. Rend. Soc. De biol. (Paris) 92, 1442-1443 (1925).

65. Wagner, P. L. \& Waldor, M. K. Bacteriophage control of bacterial virulence. Infect. Immun. 70, 3985-3993 (2002).

66. Altschul, S. F., Gish, W., Miller, W., Myers, E. W. \& Lipman, D. J. Basic local alignment search tool. J. Mol. Biol. 215, 403-410 (1990). 
67. Loessner, M. J., Rees, C. E. D., Steward, A. B. \& Scherer, S. Construction of luciferase reporter bacteriophage A511::/uXAB for rapid and sensitive detection of viable Listeria cells. Appl. Environ. Microbiol. 62, 1133-1140 (1996)

68. Carriere, C. J. et al. Conditionally replicating luciferase reporter phages: improved sensitivity for rapid detection and assessment of drug susceptibility of Mycobacterium tuberculosis. J. Clin. Microbiol. 35, 3232-3239 (1997).

69. Schuch, R., Nelson, D. \& Fischetti, V. A. A bacteriolytic agent that detects and kills Bacillus anthracis. Nature 418, 884-889 (2002).

70. Lay, J. O. Jr MALDI-TOF mass spectrometry of bacteria. Mass Spectrom. Rev. 20, 172-194 (2001).

71. Van Baar, B. L. M. Characterization of bacteria by matrix-assisted laser desorption/ionisation and electrospray mass spectrometry. FEMS Microbiol. Rev. 24, 193-219 (2000).

72. Hamels, S. et al. Consensus PCR and microarray for diagnosis of the genus Staphylococcus species and methicillin resistance. BioTechniques 31, 1364-1366, 1368, 1370-1372 (2001).

73. Uhr, J. W., Finkelstein, M. S. \& Baumann, J. B. Antibody formation: III. the primary and secondary antibody response to bacteriophage $\varphi \times 174$ in guinea pigs. J. Exp. Med. 115, 655-670 (1962).

74. Lederberg, J. Smaller fleas... ad infinitum: therapeutic bacteriophage redux. Proc. Natl Acad. Sci. USA 93, 3167-3168 (1996).
This review stresses the need for additional research to facilitate the use of these viruses as safe and effective therapeutic antibacteria agents.

75. Knight, J. Superbugs reveal chink in armour. Nature $\mathbf{4 1 7}$ 477 (2002).

76. Kilman, S. FDA restricts antibiotic use in livestock to protect people. The Wall Street Journal D3 (12 September, 2002).

77. Merril, C. R. et al. Isolation of bacteriophages from commercial sera. In Vitro 8, 91-93 (1972).

78. Merril, C. R. Phage in human vaccines. Science $\mathbf{1 8 8}, 8$ (1975).

79. Bernhardt, T. G., Wang, I-N., Struck, D. K. \& Young, R. A protein antibiotic in the phage $\mathrm{Qb}$ virion: diversity in lysis targets. Science 292, 2326-2329 (2001).

80. Nelson, D., Loomis, L. \& Fischetti, V. A. Prevention and elimination of upper respiratory colonization of mice by group A streptococci by using a bacteriophage lytic enzyme. Proc. Natl Acad. Sci. USA 98, 4107-4112 (2001).

81. Gaeng, S., Scherer, S., Neve, H. \& Loessner, M. J. Gene cloning and expression and secretion of Listeria monocytogenes bacteriophage-lytic enzymes in Lactococcus lactis. Appl. Environ. Microbiol. 66, 2951-2958 (2000).

82. Naidu, B. P. B. \& Avari, C. R. Bacteriophage in the treatment of plaque. Ind. J. Med. Res. 19, 737-748 (1932).
83. Boyd, E. F., Davis, B. M. \& Hochhut, B. Bacteriophage-bacteriophage interactions in the evolution of pathogenic bacteria. Trends Microbiol. 9 137-144 (2001)

\section{(4) Online links}

\section{Databases}

The following terms in this article are linked online to:

Online Mendelian Inheritance in Man:

http://www.ncbi.nlm.nih.gov/Omim/

Severe combined immunodeficiency

\section{FURTHER INFORMATION}

Encyclopedia of Life Sciences: http://www.els.net

Bacteriophages | bacteriophages in industry | phage display

technologies

Genomes of the T4-like Phages:

http://phage.bioc.tulane.edu/

Phage Ecology and Evolutionary Biology:

http://www mansfield ohio-state edu/ sabedon/

Phage Page:

http://www.mbio.ncsu.edu/esm/phage/phage.htm

Phage Therapy:

http://www.evergreen.edu/phage/phagetherapy.htm

Therapeutic uses of phage:

http://surfer.iitd.pan.wroc.pl/phages/phages.html

Access to this interactive links box is free online. 